index comunicación | no 10(3) 2020 | Páginas 193-213

E-ISSN: 2174-1859 | ISSN: 2444-3239 | Depósito Legal: M-19965-2015

Recibido el 14_09_20 | Aceptado el 07_10_2020 | Publicado el 12_11_2020

\title{
EL PAPEL DE LA RADIO \\ EN SITUACIONES DE CRISIS. \\ INICIATIVAS EN LA PANDEMIA \\ DEL CORONAVIRUS
}

THE ROLE OF RADIO IN CRISIS SITUATIONS. INITIATIVES IN THE CORONAVIRUS PANDEMIC

https://doi.org/10.33732/ixc/10/03Elpape

Emma Rodero-Antón

Universidad Pompeu Fabra emma.rodero@upf.edu https://orcid.org/0000-0003-0948-3400

María Blanco-Hernández

Universidad Internacional de La Rioja maria.blanco@unir.net https://orcid.org/0000-0003-1316-5341 
194

Resumen: La radio siempre ha demostrado ser un medio que se adapta fácilmente a situaciones de crisis. A lo largo de la historia, en grandes catástrofes naturales y en emergencias sanitarias, la radio ha tenido un papel protagonista gracias a que es el medio más universal, sencillo y accesible. También en la pandemia del coronavirus, la radio ha mostrado ser un medio de referencia. Por eso, este artículo tiene como objetivo mostrar la influencia de la radio en situaciones de crisis y describir las principales iniciativas que el medio está llevando a cabo relacionadas con la COVID-19. Las emisoras han tenido que adaptarse a la nueva situación con profesionales trabajando desde casa y programaciones que se han modificado con contenido sobre el coronavirus. Como en otras crisis, se ha incrementado el consumo, y el medio está ayudando a paliar los efectos psicológicos de la pandemia. Este papel central de la radio se muestra también en el número de iniciativas que diferentes radios de todo el mundo han organizado, como concursos y acciones solidarias para ayudar a todos los afectados. Una vez más, como ha ocurrido en otros momentos de emergencia en la historia, la radio vuelve a tener un papel substancial.

Palabras clave: radio; coronavirus; pandemia; crisis.

Abstract: Radio has always proven to be a medium that easily adapts to crises. Throughout history, in major natural disasters and health emergencies, radio has played a leading role because it is the most universal, simple, and accessible medium. Also, in the coronavirus pandemic, radio has proved to be a reference medium. Therefore, this article aims to show the radio's influence in crises and describe the main initiatives that the medium is carrying out about COVID-19. The radio stations have had to adapt to the new situation with professionals working remotely and programs that have been modified with content about the coronavirus. As in other crises, consumption has increased, and the medium is helping to alleviate the psychological effects of the pandemic. This central role of radio is also shown in the number of initiatives that different radio stations worldwide have organized, such as contests and solidarity actions to help all those affected. Once again, as it has happened at other emergency times in history, radio plays a substantial role.

Keywords: Radio; Coronavirus; Pandemic; Crisis. 


\title{
1. Introducción
}

A lo largo de la historia, la radio siempre ha demostrado ser el medio que mejor se ha comportado en situaciones de crisis (Spence, Lachlan, McIntyre y Seeger, 2009; Rodero, 2020). Gracias a sus características y a la confianza que genera, el medio radiofónico ha tenido un papel protagonista y ha acompañado a los ciudadanos en los momentos más difíciles. Como reconocimiento a esta labor, la UNESCO dedicó el Día Mundial de la Radio en 2016 a la radio en situaciones de emergencia y desastre. Un mensaje muy importante en ese momento fue que la radio salva vidas. En esa fecha, la senadora de la UNESCO, Loren Legarda, destacó la contribución de la radio en este tipo de situaciones.

\begin{abstract}
El trabajo de los profesionales de la radio es crucial en la preparación y gestión de desastres. Pueden difundir avisos y advertencias tempranas para que las comunidades se preparen con anticipación a los peligros naturales como los tifones. Además, cuando se trata de responder a las emergencias, la radio está en el terreno dentro de las primeras 24 horas de un desastre para transmitir información de salud y otra información vital a través de las ondas aéreas (UNDRR, 2016).
\end{abstract}

En grandes catástrofes naturales como tifones, huracanes, sunamis o terremotos y, especialmente en zonas vulnerables como el continente africano, la radio ha sabido reaccionar de manera rápida y dar respuesta a las situaciones difíciles, ofreciendo información actualizada y ayudando con ello a la población a tomar medidas de protección y decisiones que pueden salvar vidas (Spence et al., 2009). Pero también en crisis políticas, como golpes de estado o atentados, o sanitarias como pandemias, la radio ha tenido un importante papel. En la historia de España, por ejemplo, hay dos momentos especialmente destacados para la radio: la conocida noche de los transistores, tras el golpe de estado del 23 de febrero de 1981, o los atentados terroristas del 11 de marzo de 2004 en Madrid, por mencionar sólo los casos más sobresalientes.

En la actual crisis provocada por la COVID-19, la radio vuelve a destacarse como medio esencial para mantenerse informado, de acuerdo con el estudio de Rodero (2020). Los resultados indican que la radio es el medio que obtiene mejor nota en el tratamiento de la información de la pandemia. Además, es el medio considerado como más creíble y neutral y el que los oyentes consideran más cercano, el que más distrae y hace sentir en compañía. Este papel central del medio en la pandemia se muestra también en el gran número de iniciativas que diferentes radios en todo el mundo han puesto en marcha. Así pues, la radio es un medio que, por sus características y la confianza que suscita, es idóneo para dar servicio a la sociedad en momentos conflictivos. Por tanto, este artículo tiene como objetivo general mostrar el papel de la radio en situaciones de crisis y, como propósito específico, describir las principales iniciativas que el medio 
está llevando a cabo relacionadas con la COVID-19. Para ello se ha llevado a cabo una revisión del estado de la cuestión que ha permitido determinar la importancia de la radio en estas situaciones. Además, un análisis pormenorizado de la información facilitada por las principales emisoras de radio tras la aparición de la pandemia, tanto nacionales como internacionales, ha permitido recopilar las iniciativas más interesantes puestas en marcha en cada una de ellas.

\section{Marco teórico}

La importante contribución que la radio ha tenido en situaciones de crisis o de emergencia se debe principalmente a dos factores, uno interno y otro externo. El interno son las propias características de la radio como medio, mientras el externo sería la percepción positiva o el impacto psicológico que genera en los oyentes. Por tanto, una de las razones tiene que ver con el propio medio mientras la otra se refiere a su audiencia.

\subsection{Características de la radio}

Las características de la radio que la hacen destacar en situaciones de crisis son que es el medio más universal, más sencillo técnicamente con un bajo coste y más accesible.

En primer lugar, la radio es el medio más universal. La radio fue el primer medio de comunicación de masas y aún hoy sigue siendo el más utilizado en el mundo, el que alcanza a un mayor número de personas. Tiene una alta tasa de penetración de alrededor del $95 \%$ en todos los segmentos de población (UNESCO, 2012). Por ejemplo, en Estados Unidos, la radio llega a más ciudadanos a la semana (alrededor de un 94\%), que ningún otro medio, incluido la televisión (Nielsen, 2018). En España, la tasa de penetración está alrededor del $60 \%$ (EGM, 2020). Pero lo que es más importante es que la radio llega donde otros medios no pueden hacerlo, por ejemplo, a zonas deprimidas, locales o rurales (Mudavanhu, 2014). Esto es esencial en lugares donde el acceso a Internet todavía es limitado, como por ejemplo en África. En este continente el $80 \%$ de la población tiene una radio, lo que hace que sea la principal fuente de información para millones de personas, especialmente en zonas rurales (UNESCO, 2012; Hudson, Pelletier y Sullivan, 2017).

La penetración geográfica se completa con la accesibilidad. No hace falta tener estudios para entender los mensajes del medio, ni un alto nivel socioeconómico para escuchar la radio. Por eso, juega un papel social, educativo y cultural muy relevante. La radio se ha convertido en un medio idóneo para alcanzar a las comunidades más remotas y a las personas más vulnerables: analfabetos, discapacitados, invidentes o personas pobres. Por tanto, tiene el 
potencial de llegar a cualquier persona, sin discriminación alguna, independientemente de su nivel educativo, económico, o social.

La radio es un medio adecuado para ejercer una importante función educativa informando sobre temas de salud o abordando problemas psicológicos una vez ocurre la catástrofe. También para contribuir a minimizar sus efectos, como ocurrió en España en 1962 tras las riadas del Vallés. Entonces, Radio Barcelona puso en marcha una maratón llamada Operación Dinero para recaudar fondos que permitieran paliar el desastre. El conocido locutor de radio, Joaquín Soler Serrano, inició la campaña en los micrófonos de Radio Barcelona para todas las emisoras de la SER. Fue una maratón de horas de radio a pie de calle para conseguir todo lo necesario para los damnificados por las inundaciones. Hasta 10.000 personas se llegaron a congregar en las puertas de la emisora para realizar una donación. La campaña logró recaudar alrededor de 26 millones de pesetas en cuatro días, además de material de todo tipo. Joaquín Soler Serrano consiguió el Premio Ondas por esta campaña, además del agradecimiento de todos los ciudadanos de la zona afectada (Balsebre, 2002). En este caso, la respuesta de la población superó todas las expectativas.

Otra iniciativa donde la radio ha mostrado su solidaridad en la historia de España fue el programa Ustedes son formidables (Cadena SER, 1960-1977) de Alberto Oliveras que buscaba recaudar fondos para ayudar a los ciudadanos en situaciones complicadas. Por ejemplo, en 1961 Sevilla vivió la peor riada de su historia al desbordarse el río Tamarguillo. El programa de Oliveras consiguió recaudar entonces tres millones de pesetas (Balsebre, 2002). Estas iniciativas ponen de manifiesto el poder de movilización de la radio en situaciones de crisis.

En segundo lugar, la radio es un medio técnicamente sencillo y barato. Gracias a la simplicidad técnica que implica un bajo coste, la radio ha desempeñado un papel protagonista en catástrofes en las cuales ningún otro medio ha podido cubrir lo que pasaba. En estas situaciones, cuando otros medios dejan de emitir, cuando no hay electricidad, la radio puede continuar informando porque apenas necesita infraestructura técnica para funcionar (Spence et al., 2009). Basta un transmisor, una antena, un ordenador y un micrófono. De hecho, es posible instalar una pequeña estación FM de 40 vatios por menos de 4.000 dólares americanos (UNESCO, 2012).

Esta capacidad para mantenerse activa aún en las peores situaciones se ha demostrado en muchas catástrofes en todo el mundo. Tormentas, tempestades, terremotos, ciclones, sunamis o inundaciones no han impedido que la radio siga funcionando, haciendo llegar información crucial para la ciudadanía en esos momentos tan complicados. Saber actuar para salvar vidas o ayudar a otros en situaciones de emergencia es fundamental y aquí la radio ha tenido un 
papel muy importante transmitiendo información vital. En estas situaciones, la radio local ha jugado un papel decisivo (Hindman y Coyle, 1999).

Es difícil cuantificar todas las catástrofes en las que la radio ha tenido un papel destacado, pero Hugelius, Adams y Romo-Murphy (2019) han realizado una investigación donde han contabilizado trece artículos entre 2007 y 2015 dedicados a analizar la actuación humanitaria de la radio. Estos estudios han descrito el papel de la radio en catástrofes como la epidemia de Ébola en África, el terremoto de Haití, el tifón de Filipinas o varios huracanes en Estados Unidos. En estos desastres, la radio no solo ha contribuido ofreciendo información sobre lo que estaba pasando y sobre cómo actuar, sino que en muchas de las situaciones de emergencia han provisto a los ciudadanos de información relevante en materia sanitaria. Así ocurrió tras el huracán Katrina o en la epidemia de Ébola en África (Hugelius et al., 2019).

En España, el caso más significativo donde la radio, gracias a su simplicidad técnica, se convirtió en protagonista en una situación de emergencia fue la conocida como "noche de los transistores" tras el golpe de estado del $23 \mathrm{de}$ febrero de 1981. Ese día se investía a un nuevo presidente en el Congreso de los Diputados. El único medio que retransmitía en directo el acto era la radio. Cuando se produjo el golpe de estado, el técnico de la Cadena Ser, Mariano Revilla, hábilmente dejó abierta una línea de sonido con los estudios de la emisora $\mathrm{y}$, de esta manera, todos los ciudadanos pudieron escuchar al momento todo lo que estaba sucediendo en el Congreso (Ser, 2011).

Así que los golpistas tomaron RTVE, pero no pudieron impedir que la radio, en este caso la Cadena Ser, continuara transmitiendo en tiempo real lo que estaba ocurriendo. Del 23 al 24 de febrero se vivió la noche más intensa de la radio en España, la "noche de los transistores" porque los ciudadanos se mantuvieron pegados a estos aparatos de radio para seguir de cerca lo que estaba ocurriendo. Así pues, la radio jugó un papel esencial en el transcurso de los hechos, factor que incluso cambió la propia concepción del medio desde aquel momento. Según el entonces director de la SER, Fernando Onega, la radio pasó de convertirse de «un medio de entretenimiento a un medio de información con toda la credibilidad» (Lamata, 2012).

En tercer lugar, la radio es el medio más accesible. El medio radiofónico se puede consumir a cualquier hora del día y de la noche y en cualquier lugar (Savage y Spence, 2014). Por tanto, la situación de conflicto no suele afectarle demasiado. El medio radiofónico es capaz de reaccionar de manera rápida y de ofrecer información casi al mismo tiempo que se produce un suceso mientras los ciudadanos pueden informarse de lo que ocurre en breve tiempo con un simple transistor. Además, la radio es un medio fácil de escuchar que no 
demanda atención exclusiva. Eso hace que, aún en situaciones complicadas, pueda seguir acompañando a las personas porque la escucha permite realizar otro tipo de actividades al mismo tiempo. Por tanto, es un medio que acompaña a las personas en el día a día pase lo que pase, adaptándose fácilmente a situaciones que demandan un consumo inmediato de información.

En los atentados del 11 de marzo de 2004 en Madrid, la radio jugó un papel decisivo informando minuto a minuto de lo que estaba sucediendo. De nuevo, como en estos momentos históricos, el consumo de radio se incrementó debido a la necesidad de los ciudadanos de estar informados (López, 2004). Pero lo que convirtió el momento en un hecho excepcional fue que la radio contribuyó a formar una determinada interpretación del acontecimiento. La Cadena Ser se convirtió en protagonista de la información durante esos cuatro días por el cuestionamiento que realizó sobre la autoría del atentado, en contra de la versión oficial del Gobierno (Rodero, Pérez-Maíllo y Tamarit, 2009).

\subsection{Percepción del medio}

Junto a las propias características de la radio, el factor externo, es decir, la percepción que los oyentes tienen del medio también es un componente significativo en situaciones de crisis. La radio puede ejercer una relevante influencia en la población gracias precisamente a su alto nivel de credibilidad y a su beneficio psicológico.

Una de las razones más importantes que decide a los ciudadanos a mantenerse informados por la radio en situaciones de crisis es la confianza que tienen en el medio. A lo largo de los años, la radio se ha erigido como el medio más creíble, por encima incluso del medio de masas por excelencia, la televisión. A nivel europeo, los datos del Eurobarómetro 2018 (2017) señalan un nivel de credibilidad para la radio de un $60 \%$, seguido de la televisión (51\%) y la prensa (47\%). Según esta misma fuente, en España el nivel de confianza está en el 52\%, también por encima del resto de medios. El estudio de Rodero (2020), realizado en el momento del confinamiento, mostró la misma tendencia. En la encuesta realizada a una muestra de oyentes, la radio consiguió el nivel más alto de credibilidad y confianza. Además, fue el que, según los encuestados, ofrece habitualmente una información más neutral e imparcial. También la encuesta de Havas Media Group (2020), realizada durante la crisis del coronavirus, mostró que los ciudadanos confiaban mayoritariamente en la radio.

En relación con el impacto psicológico de la radio, son muchas las catástrofes donde el medio ha provisto a los ciudadanos de información sanitaria relevante para actuar y disminuir los efectos negativos, pero también después de los acontecimientos para paliar los estados psicológicos negativos que comporta haber vivido una situación traumática (Hugelius et al., 2019). En este 
sentido, la radio ha mostrado ser un medio con un gran poder terapéutico (Cortés-Fuentes y Correyero-Ruiz, 2017) que puede ayudar a las personas a superar depresiones, momentos de estrés o incertidumbre; todos ellos estados psicológicos comunes en momentos de crisis. En el estudio de Rodero (2020), los oyentes dijeron tener un sentimiento mayoritario de interés por lo que acontecía, pero afirmaron estar viviendo la situación con tristeza, miedo y angustia. En este contexto, la parte positiva es que los encuestados de este estudio valoraron la radio como el medio más cercano, el que más les distrae, les hace sentir en compañía, reduce su soledad, les hace sentir felices y reduce sus niveles de ansiedad y sus preocupaciones. Por tanto, estos datos demostraron el impacto psicológico que la radio puede tener en sus oyentes. Sobre este aspecto, existen muchas iniciativas en todo el mundo donde la radio ha demostrado su función educativa, ayudando a los ciudadanos a resolver problemas y promoviendo un bienestar psicológico. Por ejemplo, una iniciativa muy interesante, porque además está destinada a los jóvenes, es Children's Radio Foundation. Se trata de una red de emisoras que presentan jóvenes de distintos países africanos donde se abordan aquellos temas que les preocupan. En definitiva, la radio, gracias a la compañía y cercanía que proporciona, ejerce una influencia psicológica que es crucial en momentos de incertidumbre.

\section{Efectos del coronavirus en la radio}

La llegada de la pandemia ha hecho que la sociedad modifique los hábitos y costumbres, algo que también le ha ocurrido a la radio, entrando a formar parte del entorno familiar y como refugio y apoyo psicológico para muchas personas. Esta situación ha convertido a los mayores en las personas más vulnerables en la crisis del COVID-19, y, por ende, en los que más necesitan la radio. No obstante, este aislamiento ha supuesto a su vez una oportunidad para que los más jóvenes conozcan la radio como medio de información (Espinosa, 2020).

Las emisoras de radio han sido conscientes de que, a raíz de este nuevo escenario, muchas personas buscaban una relación más cercana con el medio, basada en el diálogo interno, donde pudieran mantener una conversación permanente, una vía de escape y descanso, junto a momentos de diversión y distracción. La radio ha dado respuesta a esta necesidad, por un lado, informando sobre el día a día y la crisis con espacios informativos y con contenidos dirigidos a analizar o explicar los acontecimientos y, por otro lado, ha buscado sensibilizar y persuadir a la población para saber cómo actuar durante la crisis y afrontar la situación de forma positiva (García, 2020; Balarabe, 2020).

Según Rus y Zamora (2020), los oyentes buscan en la radio recibir la información más completa posible sobre la actualidad, pero también la conciben como una fuente de distracción en los momentos difíciles. La locutora del 
programa Buenos días, Javi y Nieves (Cadena 100, 1992-actualidad), Mar Amate, señala lo siguiente: «Quizás sea más fácil informar que entretener porque la línea que separa el humor divertido del doloroso es muy fina». Realizar esta adaptación por parte del medio les ha supuesto un gran esfuerzo y ha sido necesario modificar el programa de manera drástica para ajustarse a la nueva situación. Uno de esos cambios consiste en que entre canción y canción han abierto una sección para hablar con los oyentes. De esta manera, les cuentan sus experiencias durante el confinamiento y animan a los seguidores a dejar mensajes para los que están en cuarentena o ingresados en hospitales. En definitiva, intentan llegar de manera más humana a los oyentes.

Al igual que ha ocurrido con otros medios de comunicación, ante el riesgo de contagio, la radio ha tenido que adaptarse a la nueva situación y modificar su forma de trabajar, estableciendo nuevos protocolos para no exponer la salud de los profesionales ni la de sus familiares. El cambio principal ha sido que la mayoría ha trabajado desde casa, lo que ha hecho que numerosos programas hayan pasado a emitirse desde los domicilios de los presentadores. Un ejemplo es la Cadena Cope, donde tan solo han asistido al trabajo de manera presencial entre un 20 y un 30\% de los trabajadores (Rus y Zamora, 2020). Aun así, la radio ha sabido adaptarse a esta nueva situación. Tal y como muestra un estudio llevado a cabo en Reino Unido, las estaciones de radio comunitarias han innovado y han mejorado su ingenio en la presentación de programas, proporcionando entretenimiento y compartiendo información importante (Coleman, 2020).

Para facilitar la adaptación a la nueva situación, algunos medios han desarrollado recursos didácticos. Uno de ellos, Radio UNDAV, ha creado un manual de procedimiento para los operadores de la radio a través del cuál se explican los mecanismos técnicos para poder desarrollar tareas de manera remota (Casajús y Giorgi, 2020). Por su parte, Ferraretto y Morgado (2020) han elaborado una guía en la que ofrecen pautas y consejos para comunicar de manera eficaz durante la COVID-19, herramientas centradas en que la calidad del medio no se vea afectada por la nueva situación.

Otro efecto de la pandemia que ha impactado de manera directa en la radio, pero en este caso de forma negativa, ha sido el descenso de publicidad, lo que ha hecho que algunas emisoras hayan necesitado apoyo por parte de los Gobiernos (Coleman, 2020). La Asociación Española de Radio Comercial (AERC) ha calculado que el descenso en la facturación publicitaria ha alcanzado el $80 \%$ en comparación con el mismo periodo del año anterior, lo que hace que algunas emisoras pasen a estar en situación de riesgo (Europa Press, 2020). Por ello, las emisoras de radio comercial han pedido ayuda al Gobierno para 
afrontar el descenso de inversión publicitaria. Es una situación paradójica si tenemos en cuenta el papel de la radio en la crisis y el respectivo aumento de audiencia que se ha registrado.

\subsection{Consumo de radio durante la pandemia}

Como ha ocurrido en otros momentos difíciles de la historia, en esta pandemia $\mathrm{y}$, especialmente durante el confinamiento, la radio ha incrementado el número de oyentes y el tiempo de exposición (Havas Media Group, 2020; Rodero, 2020). Varias investigaciones realizadas tanto en España como fuera del país muestran que el consumo de radio ha subido de forma notable debido a la mayor demanda de información, pero también gracias a valores tales como la accesibilidad y la credibilidad del medio. En España, el estudio de Rodero (2020) registró un aumento de consumo de radio durante la pandemia de casi un punto. La mayoría de los oyentes la escucharon entre una y dos horas al día, entre 30 minutos y una hora y entre dos y tres horas. La franja horaria más demandada siguió siendo la mañana, pero con el confinamiento la escucha se repartió más a lo largo del día, especialmente subieron la tarde y el mediodía. Las emisoras con un mayor incremento fueron las generalistas convencionales mientras bajaron las musicales. Un dato importante de este estudio, y que difiere del tradicional oyente de radio, es que los oyentes escucharon más de dos estaciones durante el confinamiento: una o dos emisoras convencionales con una o dos emisoras musicales, y no todas son de la misma línea ideológica.

Esta tendencia de consumo ascendente durante la pandemia se ha registrado también en otros países. En el Reino Unido, Radiocentre (2020) ha contabilizado un incremento de escucha en la radio comercial de una hora y 45 minutos. También emisoras con público infantil como Fun Kids han ampliado las horas de emisión destinadas a los más pequeños. La BBC (2020) cifra el aumento de consumo en un 18\%. En Italia, según la Asociación Europea de Radio (AER, 2020), se ha incrementado el número de oyentes un 2,4\%. En Estados Unidos ha habido un aumento en el consumo del 28\% (Nielsen, 2020). En Chile cuatro de cinco personas escucharon la radio a lo largo de la semana, y dos tercios lo han hecho diariamente (Ipsos, 2020). En Australia, los oyentes han escuchado un promedio de una hora y 46 minutos más de radio a la semana durante la pandemia (Commercial Radio Australia, 2020). Además, el 72\% de los australianos están escuchando tanta o más radio durante esta crisis. En la India, el $82 \%$ de la población ha estado escuchando radio durante la pandemia con un incremento del 23\% (Chawla, 2020). En Sudáfrica, una encuesta llevada a cabo por la National Association of Broadcasters (NAB) cifra en un 36\% los oyentes que dicen estar escuchando más radio a causa de la pandemia. 
Aparte de la demanda de información, una parte del incremento del consumo se debe a la credibilidad del medio. Según López-Rico, González-Esteban y Hernández-Martínez (2020), la radio es uno de los medios más confiables entre las personas que tienen un nivel de formación superior, y por tanto su consumo ha sido notable durante el confinamiento. Desde una perspectiva demográfica, este crecimiento en el consumo se incrementa de manera significativa a medida que aumenta la edad (Igartua, Ortega-Mohedano y Arcila-Calderón, 2020). Otra característica del consumo que ha variado durante la pandemia ha sido el lugar de escucha. Antes del confinamiento, los espacios más demandados eran el trabajo, los desplazamientos en coche o transporte y los paseos al aire libre. En cambio, la nueva situación ha trasladado la escucha al hogar. Esto ha provocado que los canales se amplíen, como sucede en Estados Unidos y Reino Unido, donde ha aumentado la escucha a través de dispositivos como aplicaciones de móvil y altavoces inteligentes (Nielsen, 2020). Junto a estas distintas formas de consumo de radio, también se ha visto incrementada la modalidad en remoto motivada también por el consumo en el hogar (Edison Research, 2020). Otro aspecto que se ha modificado son los hábitos de escucha. En España, antes la radio se consumía individualmente, pero durante el confinamiento se comenzó a escuchar en compañía, en familia, en lugares como el salón y la cocina y mientras se realizaban tareas en el ámbito doméstico, tales como limpiar o cocinar (Rodero, 2020).

\subsection{Iniciativas de radio durante la pandemia}

La mayoría de las emisoras de radio se han visto obligadas a modificar su programación y han tenido que ofrecer contenido alternativo debido a la crisis del coronavirus. Tanto a nivel nacional como internacional, han llevado a cabo diversas iniciativas relacionadas con la creación de programas informativos y de entretenimiento, mayoritariamente basadas en elaborar contenido específico sobre el coronavirus, lo que se ha convertido en reclamo por gran parte de la audiencia.

En el ámbito nacional, las emisoras han creado algunos podcasts dedicados a analizar la pandemia, algunos proporcionando información específica y de actualidad, como el denominado Crónicas de un virus en El País (De Vega y Morales, 2020), En tiempo de pandemia en El Español, o Especial coronavirus. Todo lo que se sabe de la pandemia del COVID-19 de Cadena Ser, destacado por utilizar la técnica del storytelling para contar lo que ocurre con el coronavirus a través de expertos. Otros, sin embargo, se han centrado en temáticas más concretas como ocurre en Cuando fuimos ciegos de Onda Cero, podcast que hace un recorrido por los ochenta días que transcurren desde la detección de la COVID19 en China, hasta el decreto del Estado de Alarma en España, o Amor en tiempos de coronavirus de Cadena Cope, en el que se cuentan historias de personas 
en torno a la situación que vive el mundo y que son ejemplos de fe, esperanza y superación (Bretos y Olazábal, 2020). Además, en Cope.es se ha creado un consultorio sobre salud, economía, deporte y religión con destacados expertos para resolver cuestiones sobre la enfermedad y sus consecuencias en cada uno de los ámbitos. Otro ejemplo es Radio María, emisora que también ha incluido en su programación un Especial COVID-19, donde además de proporcionar información sobre la pandemia, se reza por los más necesitados.

Estas iniciativas también se han llevado a cabo en el ámbito internacional, donde las emisoras han creado programas de contenido específico en los que se analiza la actualidad sobre el coronavirus. La BBC ha producido Coronavirus Global Update, que consiste en un resumen diario sobre la propagación del virus, con informes de las áreas afectadas, detalles de la información médica más reciente y el impacto que produce en la salud, los negocios y viajes. Junto a ello, The Coronavirus Nescast emitido por BBC Radio 5, es un programa diario en el que se ofrece lo último sobre la pandemia del coronavirus y donde se analiza la información más reciente sobre salud pública. También la BBC ha producido tres episodios para recordar lo que sucedió en 1918, en la conocida como gripe española, que mató a más de 50 millones de personas en todo el mundo. Son tres capítulos dedicados a explicar los orígenes y síntomas de la epidemia, así como su impacto en Inglaterra y en el mundo. Relacionado con esta pandemia, Radio Influenza recogió los principales testimonios de lo que fue la gripe de 1918. Radio Influenza es un trabajo de radio arte realizado por Jordan Baseman, un artista americano afincado en Londres. El artista decidió manipular las voces con los testimonios para que sonaran artificiales representando la emisión de un «futuro distópico» (Ulaby, 2020). Estas voces leen fragmentos de artículos de periódico de 1918 relativos a la gripe española. Este es un ejemplo de una entrada.

Un hombre que tiene un resfriado puede lanzarlo fácilmente a doce pies con un estornudo. Por lo tanto, debe mantenerse a distancia. Estornudar y toser sin protegerse por un pañuelo debe ser considerado como un asalto (Radio Influenza, 2 de octubre de 1918).

Estos testimonios reflejan no solo lo que pasó, sino también el impacto psicológico entre la población (con numerosos suicidios) y las noticias falsas, que también existieron en la época. En aquellos momentos se atribuía la pandemia a los submarinos alemanes, al jazz, a los inmigrantes y a los judíos (Ulaby, 2020). Como podemos observar, la radio nos recuerda que la historia se repite y percibimos varias similitudes entre esta pandemia y el coronavirus en 2020.

Otros ejemplos de iniciativas sobre el COVID-19 son Coronavirus Daily Briefing, de Kottke Ride Home, un programa de actualización diaria de 15 minutos de duración. En Latinoamérica las iniciativas son similares, destacando por 
ejemplo el podcast Prevenir, atender e informar de Radio Educación en México, y Informativo Especial Coronavirus en Radio UNDAV en Argentina. No obstante, las emisoras de radio también han creado contenido específico, como la CNN con el programa Coronavirus: Fact vs Fiction en el que se abordan cuestiones de la pandemia, o The Daily de The New York Times, a través del cual se analiza por qué Estados Unidos no estaba preparado para la COVID-19. En Australia, la ABC ha puesto en marcha Coronacast, un podcast que responde preguntas relacionadas con el virus. No menos interesante es el proyecto denominado City Road Podcast llevado a cabo por la emisora de Sidney Radio 2Ser, un podcast internacional en el que académicos de todo el mundo proporcionan grabaciones de audio sobre sus ciudades durante la COVID-19. Una lección clave de este proyecto es que algunas de las reflexiones más profundas sobre el podcasting y las ciudades bajo el virus se produjeron a través de un proceso de escritura colaborativa en lugar de a través de la producción del podcast (Rogers et al., 2020).

En el ámbito musical, una de las iniciativas que más ha calado en España ha sido la propuesta por Jordi Cruz, de Cadena 100. La idea fue utilizar la canción titulada Resistiré del Dúo Dinámico (1988) como himno de la pandemia, con la finalidad de animar a todos los ciudadanos (Fenoy, 2020). A su vez, las emisoras musicales han descubierto los buenos resultados que han tenido los conciertos emitidos a través de las redes durante el confinamiento. Un ejemplo es la iniciativa del Matadero de Madrid, que junto a cuatro plataformas de radio independiente emitieron durante 17 horas más de veinte citas sonoras (Matadero Madrid, 2020). Por su parte, Europa FM ha promovido una cita diaria Europa Home Date con su audiencia, dando acceso a contenidos exclusivos, conciertos y actividades (Europa FM, 2020-actualidad). Más participativa ha sido la iniciativa de Radio Clásica de Radio Nacional, denominada \#MusicaClasicaEnCasa, a través de la cual, ha invitado a todos los oyentes a compartir sus vídeos interpretando, cantando o escuchando sus obras favoritas (RTVE, 2020a). Esta emisora también ha querido ayudar a tranquilizar a los ciudadanos y calmar la ansiedad que la situación ha causado a través de la emisión de una canción de cuna denominada Sleep (Max Richter, 2020) durante la madrugada del 12 al 13 de abril (RTVE, 2020b).

Otro de los objetivos de las emisoras de radio ha sido incentivar la participación y el desarrollo creativo a través de concursos en los que los participantes han tenido que demostrar su ingenio, lo que en muchos casos ha servido como medio de distracción durante el confinamiento. Uno de los más destacados a nivel mundial lo ha puesto en marcha la conferencia más importante de la industria de la radio europea, tanto privada como pública, Radiodays Europe. En este año de pandemia han organizado los premios denominados Coronavirus Radio Ideas. 
Best of Awards. El objetivo ha sido reconocer a los profesionales de la radio de todo el mundo que han utilizado sus marcas y sus plataformas de manera creativa e innovadora y a los que mejor han atendido a los oyentes y a las comunidades durante la pandemia. El certamen tenía diez categorías para premiar las mejores ideas y se presentaron alrededor de 87 de diferentes países. Otro concurso a nivel mundial es STAYHOME, organizado por la Liga de Radioaficionados finlandesa (SRAL) en cooperación con Araucaria DX Group (ADXG) de Brasil y Radio Arcala OH8X de Finlandia. Se trata de un concurso de radio cuyo objetivo es reunir a unos tres millones de radioaficionados para que se saluden e interaccionen y premiar así las mejores iniciativas (EA Contest Club, 2020).

Como ya se ha mencionado, la radio tiene un fuerte poder de movilización en tiempos de crisis, por lo que también se ha utilizado para poner en marcha iniciativas solidarias, tales como el envío de radios por parte de los oyentes de Cadena 100 a los hospitales para que los pacientes pudiesen escuchar música. Panasonic (2020) se ha sumado con una donación de centenares de radios a hospitales y residencias de gente mayor. En Estados Unidos se organizó un Radiothon, en la que participaron más de 10.000 emisoras y en la que se recaudaron más de 500.000 dólares en un día para ayudar a los afectados por COVID19 (Hollabaugh, 2020). Además, se han organizado concursos a nivel local y universitario, como en Onda Cero Sagunto, con un concurso infantil de audio relatos denominado ¿Cómo acabarías con el dichoso bicho? (Onda Cero, 2020). Por su parte, la Universidad Miguel Hernández (2020) ha organizado un concurso solidario y literario de micro-relatos radiofónicos denominados Amor Confinado, cuyos premios se han destinado a una ONG.

Con el objetivo de concienciar a la población sobre la importancia de la COVID-19, la radio ha puesto en marcha diversas acciones de sensibilización. Una de las desarrolladas en Perú ha sido a través de Farmamundi y el Centro de la Mujer Peruana Flora Tristán. Estas entidades han desarrollado comerciales de radio destinados a la prevención del coronavirus y sus efectos adversos sobre la salud sexual y reproductiva, así como sobre la violencia contra las mujeres (Farmamundi, 2020). Junto a ello, la Academia Española de la Radio (2020), en colaboración con la UNESCO, ha puesto en marcha una campaña informativa sobre el coronavirus motivada por la cantidad excesiva de información generada sobre la COVID-19, a la que se ha denominado infodemia (OMS, 2020). Preocupados por la veracidad de las noticias y para combatir la propagación de informaciones falsas, la campaña de la Academia Española de la Radio ha consistido en producir una serie de anuncios con mensajes dirigidos a contrarrestar la desinformación sobre la COVID-19 y a través de las que promueven comportamientos saludables. 
Estos comerciales son de libre uso para su inserción en emisoras, diferentes medios de comunicación y redes sociales.

En definitiva, como se ha mostrado, han sido numerosas las iniciativas puestas en marcha por y a través de la radio en la situación de pandemia. Resultaría imposible mencionarlas todas en este documento, pero al menos, el recorrido realizado ofrece una visión global del tipo de acciones que se han emprendido desde el medio radiofónico.

\section{Conclusiones}

A lo largo de la historia, la radio ha sido un medio destacado en situaciones de crisis debido a que es el más universal, accesible y técnicamente con un bajo coste. La radio alcanza lugares donde otros medios no llegan, por ejemplo, zonas locales o rurales. También es accesible a todo tipo de personas, independientemente de su poder económico o nivel educativo. Además, la radio puede seguir emitiendo aún en situaciones extremas de falta de electricidad. Por eso, es un medio idóneo para abordar las catástrofes y sus consecuencias informando a los ciudadanos sobre las medidas de actuación y protección y ayudándoles a sobreponerse ante sus efectos psicológicos negativos. En España, la contribución de la radio en situaciones de crisis se ha demostrado en momentos difíciles como el golpe de estado del 23 de febrero de 1981, las riadas del Vallés en 1962 o los atentados terroristas del 11 de marzo en Madrid, por poner los ejemplos más evidentes.

Junto a estas características del medio, la percepción que los oyentes tienen de la radio también es un ingrediente importante para entender su contribución sobresaliente en momentos de crisis. El factor más importante en este sentido es que, según diversos estudios, la radio es considerada como el medio que transmite más credibilidad y confianza, aspecto crucial en situaciones de incertidumbre. En esos momentos es cuando los ciudadanos buscan tener más información, pero tiene que ser una información fiable de una fuente de confianza. Pues bien, la radio cumple con ese criterio. Pero también el medio radiofónico ha demostrado tener un efecto psicológico beneficioso en los oyentes por la sensación de compañía, cercanía y bienestar que provoca escuchar sus programas y especialmente oír la voz familiar del locutor. Por eso, algunos estudios muestran que tiene un significativo poder terapéutico. Esta característica es muy importante en situaciones de emergencia donde la radio ha actuado facilitando a los ciudadanos información en materia sanitaria a través de programas específicos y paliando en muchos casos las consecuencias psicológicas que comporta vivir una situación traumática o de incertidumbre como la actual.

En la pandemia del coronavirus, la radio ha vuelto a demostrar que es un medio de referencia. Como ha ocurrido en otras situaciones de conflicto, se ha 
incrementado el consumo debido a la necesidad de la población de estar informada sobre la enfermedad. Los estudios realizados en diversos países han registrado un aumento de manera global tanto en el número de horas de escucha como en el número de oyentes. En el caso concreto de España incluso se han registrado cambios en los hábitos de escucha. Durante el confinamiento, la radio se comenzó a sintonizar en familia y en lugares poco habituales hasta el momento como el salón. También han variado los dispositivos utilizados, con un aumento del consumo a través del teléfono móvil, los altavoces inteligentes y en la modalidad online.

Por su parte, las emisoras han tenido que adaptarse a la nueva situación modificando la programación mientras los profesionales de la radio han tenido que hacer un importante esfuerzo trabajando desde casa con escasos medios, sobre todo, al inicio de la crisis. A pesar de ello, la sencillez técnica de la radio ha sido un aliado en este aspecto que ha permitido a las estaciones seguir sus emisiones de manera regular. Las radios en todo el mundo han respondido con iniciativas de muy diversa índole. Muchas emisoras han dedicado programas o podcasts especiales a la pandemia, algunos con información de actualidad, otros repasando la historia o las causas de la pandemia, otros reflejando la realidad y sus efectos y otros con una clara vocación de servicio tratando de resolver dudas sobre la enfermedad.

Además, ha habido iniciativas dirigidas al entretenimiento como conciertos musicales con gran participación de artistas para calmar la ansiedad y el estrés causado por la situación. Junto a ello, también se han organizado concursos para fomentar la creatividad y la innovación en este medio y acciones solidarias para ayudar y apoyar a los más afectados por esta pandemia. Se constata así una vez más el poder de movilización de la radio en tiempos de crisis.

En definitiva, como ha ocurrido en otros momentos de la historia, como emergencias sanitarias, la radio vuelve a tener un papel protagonista proporcionando información valiosa a la ciudadanía para saber cómo actuar y cómo sobreponerse a la adversidad.

\section{Referencias bibliográficas}

ABC. (2020). Coronacast. https://www.abc.net.au/radio/programs/coronacast/

ACADEMIA ESPAÑOLA DE LA RADIO (2020). Campaña UNESCO sobre el COVID-19. https://soundcloud.com/user-85735287/sets/campana-radiofonicade-la-unesco-sobre-el-covid-19

AER (2020). AER special bulletin - 6th edition - Radios and COVID19 http://www.aereurope.org/aer-special-bulletin-6th-edition-radiosand-covid19-21-april-2020/ 
AIMC (2020). Audiencia General de Medios (EGM), Primera oleada de 2020. http://reporting.aimc.es/index.html\#/main/cockpit

ART19. Kottke Ride Home. https://art19.com/shows/coronavirus-dailybriefing

BBC (2020). Coronavirus: Radio listening booms while music streaming stalls. https://www.bbc.com/news/technology-52037461

BALARABE, U. B. (2020). Impact of COVID-19 and Pandemic Lockdown in India: Role of Media during Lockdown. Gangrar: Eureka Publications.

BALSEBRE, A. (2002). Historia de la Radio en España (1939-1985). Madrid: Ediciones Cátedra.

BBC (2020). Pandemic 1918. https://www.bbc.co.uk/programmes/m000j2ty

BBC. (2020) Coronavirus Global Update. https://www.bbc.co.uk/programmes/w13xtv39

BBC RADIO 5. (2020) The Coronavirus Newscast. https: //www.bbc.co.uk/programmes/m000h2xg

BRETOS, A. y OLAZÁBAL, V. (2020). Especial coronavirus: todo lo que se sabe de la epidemia del COVID-19. Cadena Ser. https://cadenaser.com/ser/2020/03/09/sociedad/1583762773_005453.html

CASAJÚS, L. y GIORGI, N. (2020). El trabajo de los medios de comunicación universitarios en la pandemia. La experiencia de Radio UNDAV y UNDAV TV. Question/Cuestión, 1(mayo), e309. doi.org/10.24215/16696581e309

Chawal, U. (2020). Audience Survey in 6 metros. AZ Research PPL. Press Release. https://www.radiodayseurope.com/news/news-asia-radio-listening-india

CHILDREN'S RADIO FOUNDATION. https://childrensradiofoundation.org/

CNN. (2020) Coronavirus: Fact vs Fiction. https://edition.cnn.com/audio/podcasts/corona-virus

COLEMAN, J. (2020). UK community radio production responses to COVID-19. https://www.brunel.ac.uk/research/Documents/Jo-Coleman-UKCommunity-Radio-Production-Responses-to-COVID-19.pdf

COMMERCIAL RADIO AUSTRALIA (2020). Radio listening up in COVID-19 lockdown http://www.commercialradio.com.au/content/mediareleases/2020/2020-04-20-radio-listening-up-in-covid-19-lockdown\#.X19UAXMZZTZ

De VeGA, C. y MoraleS, J.J. (2020). Podcast|Crónicas de un virus. El País. https: //elpais.com/sociedad/crisis-del-coronavirus/2020-03$17 /$ podcast-cronicas-de-un-virus.html

EA CONTEST Club (2020). Concurso de radio por el Covid-19. https://www.eacontestclub.com/concurso-de-radio-por-el-covid-19/

EDISON RESEARCH (2020). The infinite dial 2020. https://www.edisonresearch.com/the-infinite-dial-2020/ 
EL ESPAÑOL (2020). En tiempos de pandemia, un podcast para analizar la crisis del coronavirus. https://www.elespanol.com/ciencia/salud/20200330/tiempos-pandemia-podcast-analizar-crisis-coronavirus/477952917_0.html

ESPINOSA, M. J. (2020). La radio en la crisis de la Covid-19. Días de vino y podcast. El País.

https: / /elpais.com/elpais/2020/03/15/dias_de_vino_y_podcasts/1584271315_152798.html

EUROBARÓMETRO (2017). Media use in the European Union. Brussels: European Comission. https://op.europa.eu/en/publication-detail/-/publication/a575c1c9-58b6-11e8-ab41-01aa75ed71a1

EUROPA FM (2020). Europa FM contigo en casa. https://n9.cl/xrsb1

EUROPA PRESS (2020). Radios comerciales piden al gobierno ayudas e incentivos para poder mantener sus emisiones y el empleo. https://n9.cl/ibp9

FARMAMUNDI (2020). La radio alza su voz en Perú para sensibilizar contra el Covid-19. https: / / farmaceuticosmundi.org/la-radio-alza-su-voz-parasensibilizar-contra-el-covid-19-en-peru /

FEnOY, M. (2020). Cadena 100 y Pablo Cebrián unen al mundo de la música en 'RESISTIRÉ 2020', himno vital frente al coronavirus. https://n9.cl/i7f62

FERRARETTO, L. A. y MORGADO, F. (2020). COVID-19 and communication: a practical guide to face the crisis. Río de Janeiro: Válega.

GARCÍA, J. A. (2020). Así trabajan los medios de comunicación durante la crisis del COVID-19. Universidad Miguel Hernández.

https: / /mip.umh.es/blog/2020/03/27/asi-trabajan-los-medios-durante-la-crisis-del-covid-19/

HAVAS MEDIA GROUP (2020). Estudio del impacto del coronavirus en hábitos y medios. Madrid: Havas Group. https://n9.cl/j15gb

Hollabaugh, L. (2020). Radio Cares Emergency Radiothon Raises \$ 500,000 for Feeding America. Music Row. https: / / musicrow.com/2020/05/radio-cares-emergency-radiothon-raises-500000-for-feeding-america/

Hudson, H. E., Pelletier, B. y Sullivan, B. (2017). Using radio and interactive ICTs to improve food security among smallholder farmers in Sub-Saharan Africa. Telecommunications Policy, 41 (7-8), 670684. doi.org/10.1016/j.telpol.2017.05.010

HugELIUS, K., ADAMS, M. y Romo-MuRPHY, E. (2019). The power of radio to promote health and resilience in natural disasters: a review. International journal of environmental research and public health, 16(14), 2526. doi.org/10.3390/ijerph16142526 
IXGARTUA, J., ORTEGA-MOHEDANO, F. y ARCILlA-CALDERÓN, C. (2020). Usos de la comunicación en los tiempos del coronavirus. Un estudio transcultural. El Profesional de la información, 29(3), 1-16. doi.org/10.3145/epi.2020.may.18

IPSOS (2020). Análisis de audiencias de radios. https://www.ipsos.com/sites/default/files/ct/publication/documents/2020-04/resultados_audiencia_radial_marzo_2020_3.pdf

LAMATA, J.F. (2012). Entrevista a Fernando López Ónega. http://www.periodistadigital.com/periodismo/tv/2012/02/14/fernando-onega-telecincoantena3-prisa-mundo-pais-ser-arriba-telefonica.shtml

LÓPEZ, G. (2004). El 11 m y el consumo de medios de comunicación. Sala de Prensa, 3 (71). http://www.saladeprensa.org/art565.htm

LóPEZ-RiCo, C. M., GonZÁLEZ-ESTEBAn, J. L. y HERnÁNDEZ-MARTínEZ, A. (2020). Polarización y confianza en los medios españoles durante el Covid-19. Identificación de perfiles de audiencia. Revista Española de Comunicación en Salud, Supl. 1, 77-89. doi.org/10.20318/recs.2020.5439

MATADERO MADRID. (2020). Matadero Día Europeo de la Música. https: / / www.mataderomadrid.org/programacion/matadero-dia-europeo-de-la-musica

MUNDAVAHU, S. L. (2014). A study of Radio Zimbabwe's messages and audiences in a time of crisis. Tesis doctoral, Universidad de Ciudad del Cabo, Sudáfrica. MuÑOZ, B. E. F. (2020). La radio cubana ante la COVID-19. Un estudio de caso. Revista Española de Comunicación en Salud, Supl. 1, 272-278. doi.org/10.20318/recs.2020.5421

NATIONAL ASSOCiation OF BRoAdCASTERS (NAB) (2020). Future Proofing Community Radio. https: / / www.nab.org.za/uploads/files/NAB_Future_Proofing_Guide_for_Community_Radio.pdf

NIELSEN (2018). Audio today 2018. How American listens. Report. New York: Nielsen. https://www.nielsen.com/us/en/insights/report/2018/state-of-the-media-audio-today-2018/

NIELSEN (2020). Radio is 'Comfort food' as media consumption rises amid Covid-19 pandemic. https://www.nielsen.com/us/en/insights/article/2020/radio-is-comfort-food-as-media-consumption-rises-amidcovid-19-pandemic/

ONDA CERO (2020). ¿Cómo acabarías con el dichoso bicho? https://n9.cl/uovd

OMS (2020). Entender la infodemia y la desinformación en la lucha contra la COVID-19. https://www.paho.org/es/file/64245/download?token $=v q D v d 7 j C$ 
PANASONIC (2020). Panasonic acompaña a los afectados por Covid-19 enviando radios solidarias a hospitales y residencias de gente mayor. https://n9.cl/bh79d

RADIOCENTRE (2020). Commercial radio sees double-digit listening uplift as UK tunes in from home during lockdown. https://www.radiocentre.org/commercial-radio-sees-double-digit-listening-uplift-as-uk-tunes-in-from-home-during-lockdown /

RADIODAYS EUROPE. (2020). Coronavirus Radio Ideas. "Best of" Awards. https://www.radiodayseurope.com/coronavirus-radio-ideas-awards

RADIO EDUCACIÓN (2020). Covid-19 - Prevenir, atender e informar. https://eradio.gob.mx/Covid-19

RADIO INFLUENZA. https://radioinfluenza.org/report-archive/

RADIO MARÍA. (2020). Podcast especial Covid-19. https://www.radiomaria.es/evento/178/podcast-especial-covid-19

RADIO UNDAV. COVID-19. (2020). Informativo especial coronavirus. http://radio.undav.edu.ar/podcasts?field_categoria_tid=141\&title=

RODERO, E. (2020). La radio: el medio que mejor se comporta en las crisis. Hábitos de escucha, consumo y percepción de los oyentes de radio durante el confinamiento por el Covid-19. El profesional de la información, 29(3), 1-15. doi.org/10.3145/epi.2020.may.06

RoDERo, E., PÉrEZ-MAíllo, A. y TAMARIT, A. (2009). El atentado del 11 de marzo de 2004 en la Cadena SER desde la teoría del 'framing'. ZER: Revista de Estudios de Comunicación, 14 (26), 81-103.

Rogers, D., HERBERT, M., WhitZMAN, C., MCCANn, E., MAGinN, P. J., WATTS, B. y NoVACEVSKI, M. (2020). The city under COVID-19: podcasting as digital methodology. Tijdschrift voor economische en sociale geografie, 111(3), 434-450. doi.org/10.1111/tesg.12426

RTVE (2020a). Radio Clásica lanza la iniciativa y ofrece una programación alternativa. https: //www.rtve.es/rtve/ 20200324/radio-clasica-musicaclasicaencasa-programacion-alternativa/2010722.shtml

RTVE (2020b). "Sleep" en Radio Clásica, una canción de cuna para un mundo en confinamiento. https://www.rtve.es/rtve/20200408/radio-clasicaemite-cancion-cuna-calmar-ansiedad-confinamiento/2011677.shtml

RUS, O. y ZAMORA, I. (2020). Así se hace radio en pandemia. https://www.abc.es/play/television/noticias/abci-coronavirushace-radio-plena-pandemia-202003250938_noticia.html

SAVAGE, M. E. y SPENCE, P. R. (2014). Will you listen? An examination of parasocial interaction and credibility in radio. Journal of Radio \& Audio Media, 21(1), 3-19. doi.org/10.1080/19376529.2014.891214

SER (2011). 'La noche de los transistores', 30 años después. https://cadenaser.com/ser/2011/02/21/espana/1298249411_850215.html 
SPENCE, P. R., LACHLAN, K. A., MCintYRE, J. J. y SEEgER, M. (2009). Serving the public interest in a crisis: Radio and its unique role. Journal of Radio \& Audio Media, 16(2), 144-159. doi.org/10.1080/19376520903277005

THE NEW YORK TIMES. The Daily. https://www.nytimes.com/column/thedaily

ULABY, N. (2020). We haven't learned from history': 'Radio Influenza' is a warning from 1918. NPR, en

https: / / www.npr.org/2020/04/16/831053620/we-haven-t-learned-from-history-radio-influenza-is-a-warning-from-1918

UNESCO (2012). Statistics on Radio. https://n9.cl/0vzbc

UNESCO (2020). Recursos de audio para contrarrestar la desinformación. https://es.unesco.org/covid19/communicationinformationresponse/audioresources

UNITED NATIONS OFFICE FOR DISASTER RISK REDUCTION -UNDRR- (2016). Radio in times of disaster. https://www.undrr.org/news/radio-times-disaster

UNIVERSIDAD MIGUEL HERNÁNDEZ (2020). La UMH convoca un concurso solidario de microrrelatos. https://n9.cl/ho0p7 